\title{
Rescue Analgesic Medication Use by Patients Treated with Triamcinolone Acetonide Extended-Release for Knee Osteoarthritis Pain: Pooled Analysis of Three Phase 2/3 Randomized Clinical Trials
}

\author{
Alan J. Kivitz • Philip G. Conaghan (D) · Amy Cinar · Joelle Lufkin • \\ Scott D. Kelley
}

Received: March 13, 2019 / Published online: May 7, 2019

(c) The Author(s) 2019

\section{ABSTRACT}

Introduction: In clinical trials for knee osteoarthritis (OAK), rescue medication is commonly provided to manage uncontrolled indexknee pain. The impact of treatment on rescue medication utilization provides important information on the robustness of analgesic effect. In randomized controlled OAK trials (NCT01487161, NCT02116972, NCT02357459), intra-articular (IA) triamcinolone acetonide extended-release (TA-ER) demonstrated substantial, prolonged analgesia versus saline-placebo and TA crystalline solution (TAcs) as assessed by patient-reported pain scales. This pooled analysis assessed the impact of TA-ER on rescue medication use.

Methods: Patients $(N=798)$ with OAK (American College of Rheumatology criteria;

Enhanced Digital Features To view enhanced digital features for this article go to https://doi.org/10.6084/ m9.figshare.7998302.

\section{A. J. Kivitz ( $\square)$}

Altoona Center for Clinical Research, Duncansville, PA, USA

e-mail: ajkivitz@yahoo.com

\section{P. G. Conaghan}

Leeds Institute of Rheumatic and Musculoskeletal Medicine, University of Leeds and Leeds Biomedical Research Centre, Leeds Teaching Hospitals NHS Trust, Leeds, UK

A. Cinar · J. Lufkin · S. D. Kelley

Flexion Therapeutics, Inc., Burlington, MA, USA
Kellgren-Lawrence grade 2/3) and baseline average daily pain intensity score $\geq 5$ to $\leq 9$ (0-10 numeric rating scale) received a single IA injection of TA-ER $(N=324)$, saline-placebo $(N=262)$, or TAcs $(N=212)$. Acetaminophen/ paracetamol tablets were provided to treat uncontrolled pain (knee or otherwise). Rescue medication consumption was monitored through a daily diary; pill counts were confirmed at the clinical site. Differences in rescue medication use were measured by least-squares mean (LSM) differences, number of rescue medication tablets used per day, and in area under the effect (AUE) curves of rescue medication tablets used per week. Results: The overall number of rescue medication tablets used per day through week 24 was significantly less $(p \leq 0.05)$ for TA-ER versus saline-placebo (LSM difference, - 0.43) and TAcs $(-0.24)$. Rescue medication use was significantly $(p \leq 0.05)$ lower following TA-ER versus saline-placebo across weeks 1-12

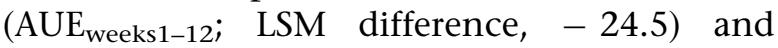

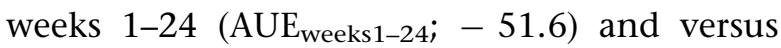

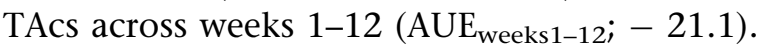

Conclusions: In patients with painful OAK, reduced rescue medication use may be a potential benefit of TA-ER and further supports its analgesic efficacy. Additional research is needed to assess whether TA-ER impacts the use of other common oral analgesics (nonsteroidal anti-inflammatory drugs, opioids) for patients with OAK.

Funding: Flexion Therapeutics, Inc., Burlington, MA, USA. 
Plain Language Summary: Plain language summary available for this article.

Keywords: Clinical trial; Corticosteroid; Intra-articular; Knee; Osteoarthritis; Rescue medication; Triamcinolone acetonide extended-release

\section{PLAIN LANGUAGE SUMMARY}

Osteoarthritis is a common chronic condition that results from the breakdown of cartilage within the joint, leading to pain, swelling, and joint stiffness. There are no drugs that can prevent or cure osteoarthritis, but treatments are available to reduce osteoarthritis pain, including acetaminophen, nonsteroidal anti-inflammatory drugs, opioids, viscosupplementation, and steroid injections. Steroid injection into the affected joint of a patient with knee osteoarthritis has been shown to reduce pain; however, because of the rapid outflow of drug from the joint, only short-term pain relief is achieved. A long-acting form of steroid that releases the active treatment slowly over time from a biodegradable bead has been shown to be effective in knee osteoarthritis. Compared with a short-acting steroid treatment, this extended-release formulation results in a longer presence of active steroid in the joint following injection. This extended-release steroid has also produced improved pain relief compared with a saline-placebo injection and a short-acting steroid injection as measured by patientreported pain scales. Another way to measure the impact of treatment on osteoarthritis pain is to monitor the use of "rescue" medication provided to participants receiving treatment during trials in case they need to manage uncontrolled index-knee pain. In the current analysis, the extended-release steroid injection reduced the need for such rescue medication, compared with both saline-placebo and a short-acting steroid injection. Reduced use of rescue medication can indicate improved pain relief and can also limit patient use of secondary medications that may have harmful side effects.

\section{INTRODUCTION}

Osteoarthritis of the knee (OAK) is a painful condition that contributes to reduced mobility and impaired quality of life $[1,2]$. Symptomatic OAK is typically managed with analgesics, including oral agents [e.g., acetaminophen, nonsteroidal anti-inflammatory drugs (NSAIDs), and opioids] and standard intra-articular corticosteroid (IACS) injections [2-4]. Although oral pain-relieving agents can be effective in alleviating OAK pain, a number of associated adverse effects limit their long-term use [2, 4-7]. Conventional IACS injections reduce pain and improve function in OAK; however, the analgesic effect of standard IACS, such as triamcinolone acetonide crystalline suspension (TAcs), may be of limited duration because of the rapid egress of corticosteroid from the joint space following injection [8-10]. Longer-acting IA pain relief treatments that reduce the long-term use of oral analgesics are needed for the management of patients with chronic OAK pain.

Triamcinolone acetonide extended-release (TA-ER) is a microsphere-enabled [75:25 poly(lactic-co-glycolic acid), nominal drug load of $25 \%(w / w)$ ] longer-acting IA agent. Pharmacokinetic data show that TA joint residency time increased and systemic exposure decreased following TA-ER injection compared with standard TAcs in patients with OAK [10]. This reduced systemic release of TA following TA-ER has been observed in several studies and may contribute to the reduced glycemic control disruption observed with TA-ER compared with TAcs treatment in patients with OAK and type 2 diabetes [10-13]. The local synovial fluid TA concentration profile following TA-ER injection is in line with the prolonged, clinically meaningful efficacy observed in randomized controlled trials of patients with OAK [13-15]. In a phase 3 study, TA-ER significantly improved mean average daily pain (ADP) intensity score compared with saline-placebo at the 12 -week primary endpoint $(p<0.0001)$ and provided continued significant improvements to week 16 $(p<0.05)$ [14]. TA-ER also provided significant improvements in the Western Ontario and McMaster Universities Osteoarthritis Index 
(WOMAC)-A (pain), -B (stiffness), and $-C$ (function) and in the Knee Injury and Osteoarthritis Outcome Score-Quality of Life scores compared with both saline-placebo and TAcs at week $12 \quad(p<0.05$; prespecified exploratory endpoints) [14]. In the same study, TA-ER demonstrated an acceptable safety profile and most adverse events (AEs) were grade 1 or 2 and nonserious [14].

It is common in clinical trials of analgesic agents for rescue medication to be issued to participants for use as needed to manage uncontrolled index-knee pain [16]. Measuring rescue medication use can provide important information on the robustness of the overall analgesic effect because effective pain medications should reduce the need for rescue medication. According to guidance from the US Food and Drug Administration, rescue medication can be used to define a "responder" in clinical studies and can be used as a primary outcome measure and, furthermore, rescue medication use should be considered a secondary endpoint when pain intensity is the primary efficacy endpoint [17]. The use of rescue medication is frequently cited as a secondary endpoint or an additional efficacy measure in clinical trials evaluating the efficacy of other IA agents for OAK [18-23]. However, evidence is limited regarding the impact of conventional IACS on rescue medication use. One meta-analysis reported no difference in the proportion of rescue medication use with IA injection of conventional IACS [18]. Conversely, in a phase 3 study of TA-ER, rescue medication (acetaminophen/paracetamol) was provided to patients to manage uncontrolled index-knee pain, and use was evaluated as an additional efficacy endpoint; significantly fewer rescue medication tablets were needed per week by patients treated with TA-ER than by those treated with saline-placebo through week 24 $(p<0.05)$ [14]. To better understand the impact of TA-ER treatment on the need for rescue medication across the TA-ER clinical program, we pooled available study data from three phase $2 / 3$ studies and evaluated rescue medication use in patients with OAK.

\section{METHODS}

\section{Compliance with Ethics Guidelines}

All procedures were conducted in accordance with the ethical standards of the responsible committee on human experimentation (institutional and national) and with the Helsinki Declaration of 1964, as revised in 2013. Protocols of the three clinical studies (ClinicalTrials.gov identifiers: NCT01487161, NCT02116972, and NCT02357459) contributing information to the pooled analyses were approved by governing ethics bodies at the participating sites, and patients provided written informed consent before participating in any study-related procedures.

\section{Study Design}

Full details on patient eligibility, study design, and interventions in the phase 2 [13], phase $2 b$ [15], and phase 3 [14] clinical trials included in this pooled analysis have been reported and are briefly summarized here. All studies enrolled men and women $\geq 40$ years of age whose body mass index was $\leq 40 \mathrm{~kg} / \mathrm{m}^{2}$. Participants had symptomatic OAK as defined by American College of Rheumatology OA criteria for $\geq 6$ months [24], Kellgren-Lawrence grade $2 / 3$ OA based on screening index-knee radiography [25], and baseline ADP intensity score $\geq 5$ to $\leq 9$ (0-10 numeric rating scale) for $\geq 5$ of the previous 7 days $[26,27]$. Each trial used a similar multicenter, double-blind, randomized, parallel-group, controlled design. In each trial, patients were evaluated every 4 weeks following a single IA injection through 12 or 24 weeks. Data from patients treated with saline-placebo, TAcs $40 \mathrm{mg}$, and TA-ER $32 \mathrm{mg}$ (delivered dose) were pooled for the purposes of this analysis.

\section{Concomitant Medication}

The following analgesics were considered restricted medications and were not to be taken or used during the studies: oral NSAIDs, aspirin (> $325 \mathrm{mg} /$ day), centrally acting pain medications (e.g., pregabalin, gabapentin, duloxetine, 
milnacipran), opioids, and topical therapies (e.g., topical NSAIDs, capsaicin, lidocaine patches, other local treatments) applied to the index knee. Rescue analgesic medication (acetaminophen/paracetamol 500-mg tablets) was issued to patients for use on an as-needed basis to manage uncontrolled index-knee pain or any other type of pain, and was not to be used for prophylaxis. Consumption of rescue medication was monitored through a daily diary reporting system, and pill counts were confirmed at the clinical site.

\section{Study Assessments}

The objective of the pooled analysis was to examine rescue medication use in three phase $2 / 3$ clinical trials. Results from all three studies contributed to the findings for weeks 1-12 and results from the phase $2 b / 3$ studies contributed to the findings from weeks 1-24. The mean number of rescue medication tablets used per week was computed for each patient by summing the number of tablets used in each weekly interval and dividing by the number of days of nonmissing responses in the weekly interval.

Treatment-emergent AEs (TEAEs)—defined as any $\mathrm{AE}$ with onset after the administration of study treatment or any $\mathrm{AE}$ that was present at baseline but worsened in intensity through the end of the study-were analyzed.

\section{Statistical Analysis}

Effects of IA injection treatment on rescue medication use were measured by least-squares means (LSM) at each week through week 24 for TA-ER versus saline-placebo and TAcs, analyzed with mixed effects model for repeated-measures methodology on observed data with no imputation for missing data. Area under the effect (AUE) curves of rescue medication use for TA-ER versus saline-placebo and TAcs through week 12 (AUE weeks1-12) $_{1}$ and week 24 (AUE weeks1-24 $)$ were analyzed using analysis of covariance, with study site as a covariate.

\section{RESULTS}

\section{Demographics and Baseline Disease Characteristics}

The pooled analysis included a total of 798 patients, with more patients receiving TA-ER $(N=324)$ than saline-placebo $(N=262)$ or TAcs $(N=212)$. Across the three studies, demographic and baseline disease characteristics were well balanced for the three treatment groups, including similar baseline ADP intensity scores (Table 1). Most patients were female $(58.6 \%)$ and white $(84.3 \%)$. Mean body mass index at baseline was $30.55,30.58$, and $30.15 \mathrm{~kg} / \mathrm{m}^{2}$, and OAK was Kellgren-Lawrence grade 3 in $60.8,59.5$, and $58.0 \%$ of patients in the TA-ER, saline-placebo, and TAcs treatment groups, respectively.

\section{Rescue Medication Use}

The use of rescue medication decreased following IA injection (Fig. 1a). The overall average number of rescue medication tablets used per day through 24 weeks [LSM (standard error, SE)] was $0.89(0.090)$ for TA-ER compared with 1.32 (0.100) for saline-placebo, and the total LSM difference $(95 \% \mathrm{CI})$ was $-0.43(-0.65,-0.20$; $p=0.0002$ ) for TA-ER compared with salineplacebo (Fig. 1b). Fewer rescue medication tablets were used per week by patients treated with TA-ER than saline-placebo at all time points, and the decreased use was significant $(p<0.05)$ at each of weeks $1-16$ and $19-20$ (Fig. 1a). Rescue medication use was also statistically significantly lower with TA-ER than with saline-placebo across weeks 1-12 (AUE $_{\text {weeks1-12; }}$ LSM difference, $-24.5 ; p=0.0121$ )

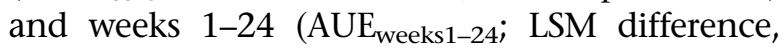
$-51.6 ; p=0.0023$; Table 2).

The overall average rescue medication tablets used per day through 24 weeks was lower for TA-ER with an LSM (SE) of 0.89 (0.090) compared with $1.13(0.113)$ for TAcs, and a total LSM difference $(95 \% \mathrm{CI})$ through week 24 of $-0.24(-0.48,-0.01 ; p=0.0433)$ for TA-ER compared with TAcs (Fig. 1b). TA-ER treatment 
Table 1 Pooled demographic and baseline characteristics

\begin{tabular}{|c|c|c|c|}
\hline & $\begin{array}{l}\text { TA-ER } 32 \mathrm{mg} \\
N=324\end{array}$ & $\begin{array}{l}\text { Saline-placebo } \\
N=262\end{array}$ & $\begin{array}{l}\text { TAcs } 40 \mathrm{mg} \\
N=212\end{array}$ \\
\hline \multicolumn{4}{|l|}{ Sex, $n(\%)$} \\
\hline Male & $139(42.9)$ & $105(40.1)$ & $86(40.6)$ \\
\hline Female & $185(57.1)$ & $157(59.9)$ & $126(59.4)$ \\
\hline Age, years, mean $(\mathrm{SD})$ & $60.5(9.16)$ & $61.4(8.73)$ & $62.1(10.06)$ \\
\hline \multicolumn{4}{|l|}{ Race, $n(\%)$} \\
\hline American Indian or Alaska Native & 0 & $1(0.4)$ & 0 \\
\hline Asian & $23(7.1)$ & $15(5.7)$ & $18(8.5)$ \\
\hline Black or African American & $26(8.0)$ & $19(7.3)$ & $13(6.1)$ \\
\hline Native Hawaiian or other Pacific Islander & $4(1.2)$ & $1(0.4)$ & $2(0.9)$ \\
\hline White & $269(83.0)$ & $226(86.3)$ & $178(84.0)$ \\
\hline Other & $2(0.6)$ & 0 & $1(0.5)$ \\
\hline BMI $\left(\mathrm{kg} / \mathrm{m}^{2}\right)$, mean $(\mathrm{SD})$ & $30.55(4.771)$ & $30.58(4.871)$ & $30.15(4.864)$ \\
\hline \multicolumn{4}{|l|}{ BMI category, $n(\%)$} \\
\hline Normal $\left(18.0-24.9 \mathrm{~kg} / \mathrm{m}^{2}\right)$ & $43(13.3)$ & $32(12.2)$ & $34(16.0)$ \\
\hline Overweight $\left(25.0-29.9 \mathrm{~kg} / \mathrm{m}^{2}\right)$ & $114(35.2)$ & $91(34.7)$ & $69(32.5)$ \\
\hline Class I obese $\left(30.0-34.9 \mathrm{~kg} / \mathrm{m}^{2}\right)$ & $100(30.9)$ & $81(30.9)$ & $72(34.0)$ \\
\hline Class II obese $\left(35.0-39.9 \mathrm{~kg} / \mathrm{m}^{2}\right)$ & $65(20.1)$ & $57(21.8)$ & $37(17.5)$ \\
\hline Morbid obesity $\left(\geq 40.0 \mathrm{~kg} / \mathrm{m}^{2}\right)$ & $2(0.6)$ & $1(0.4)$ & 0 \\
\hline Years since primary diagnosis, mean (SD) & $7.10(6.736)$ & $6.50(5.781)$ & $7.35(6.944)$ \\
\hline \multicolumn{4}{|l|}{ Kellgren-Lawrence grade, $n(\%)$} \\
\hline 2 & $127(39.2)$ & $106(40.5)$ & $88(41.5)$ \\
\hline 3 & $197(60.8)$ & $156(59.5)$ & $123(58.0)$ \\
\hline 4 & 0 & 0 & $1(0.5)$ \\
\hline \multicolumn{4}{|l|}{ Weekly average daily pain intensity score } \\
\hline $5-5.9$ & $118(36.4)$ & $99(37.8)$ & $82(38.7)$ \\
\hline $6-6.9$ & $107(33.0)$ & $78(29.8)$ & $70(33.0)$ \\
\hline$\geq 7$ & $99(30.6)$ & $85(32.4)$ & $60(28.3)$ \\
\hline
\end{tabular}

$B M I$ body mass index, $S D$ standard deviation, $T A c s$ triamcinolone acetonide crystalline suspension, $T A-E R$ triamcinolone acetonide extended-release

reduced rescue medication use compared with TAcs at each week through week 24 , with the difference reaching significance $(p<0.05)$ at weeks 6, 7, and 10 (Fig. 1a). TA-ER also significantly reduced rescue medication use across

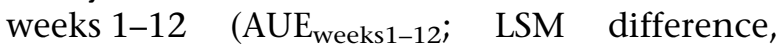




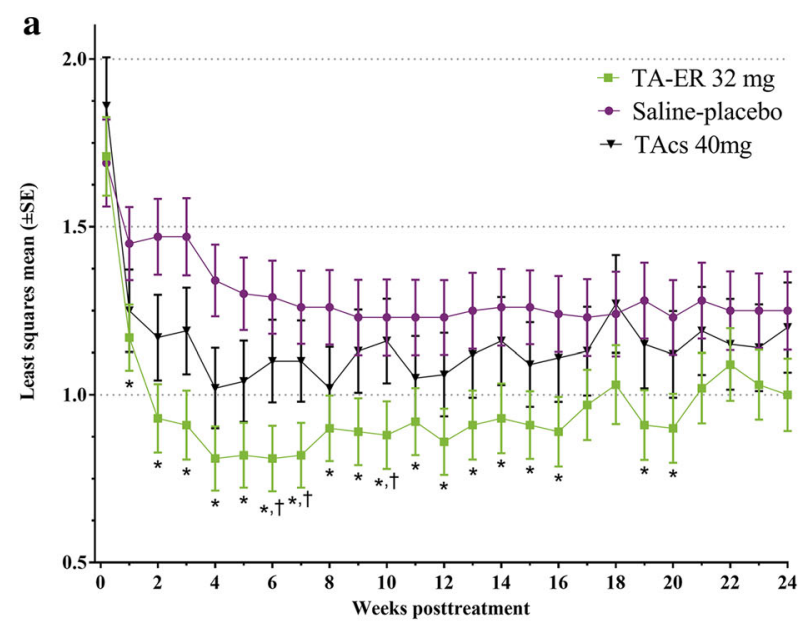

Fig. 1 Rescue medication (acetaminophen/paracetamol 500-mg tablets) use following IA treatment. a Average rescue medication tablets used per day in each weekly interval. b Average rescue medication tablets used per

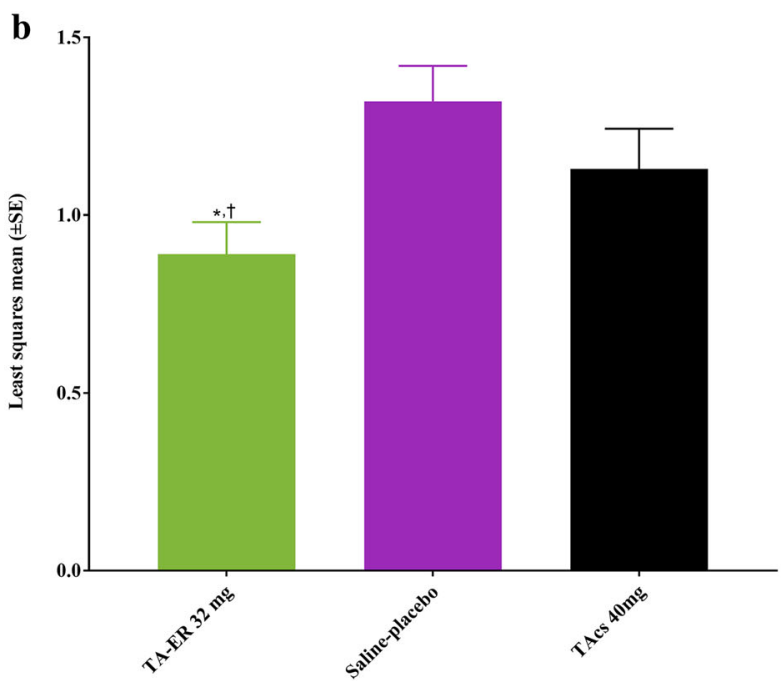

day through 24 weeks. ${ }^{*} p<0.05$ versus saline-placebo. ${ }^{\dagger} p<0.05$ versus TAcs. $I A$ intra-articular, $S E$ standard error, $T A c s$ triamcinolone acetonide crystalline suspension, $T A-E R$ triamcinolone acetonide extended-release

Table 2 Area under the effect curve of average rescue medication use

\begin{tabular}{|c|c|c|c|}
\hline & $\begin{array}{l}\text { TA-ER } 32 \mathrm{mg} \\
N=324\end{array}$ & $\begin{array}{l}\text { Saline-placebo } \\
N=262\end{array}$ & $\begin{array}{l}\text { TAcs } 40 \mathrm{mg} \\
N=212\end{array}$ \\
\hline \multicolumn{4}{|l|}{$\mathrm{AUE}_{\text {weeks1-12 }}$} \\
\hline LSM (SE) & $82.6(7.81)$ & $107.1(8.57)$ & $103.7(9.74)$ \\
\hline LSM difference vs. saline-placebo ( $p$ value) & $-24.5(0.0121)$ & & \\
\hline LSM difference vs. TAcs ( $p$ value) & $-21.1(0.0424)$ & & \\
\hline \multicolumn{4}{|l|}{$\mathrm{AUE}_{\text {weeks1-24 }}$} \\
\hline LSM (SE) & $135.6(13.48)$ & $187.2(14.80)$ & $167.9(16.82)$ \\
\hline LSM difference vs. saline-placebo ( $p$ value) & $-51.6(0.0023)$ & & \\
\hline LSM difference vs. TAcs ( $p$ value) & $-32.2(0.0731)$ & & \\
\hline
\end{tabular}

$A U E$ area under the effect curve, LSM least-squares mean, SE standard error, TAcs triamcinolone acetonide crystalline suspension, $T A$-ER triamcinolone acetonide extended-release

$-21.1 ; p=0.0424)$ and numerically reduced medication use across weeks 1-24 (AUE $\mathrm{weeks}_{\text {w-24; }}$ LSM difference, $-32.2 ; p=0.0731$; Table 2).

\section{Safety}

Pooled safety data from the trials are presented in Table 3. Most TEAEs were grade 1 or 2 , and there were no deaths. The incidence of TEAEs $(51.9,49.2$, and $56.1 \%$, respectively) and serious TEAEs (3.1, 1.1, and 1.9\%, respectively) was similar across the TA-ER, saline-placebo, and TAcs groups. Few patients discontinued because of TEAEs $(1.2,0.8$, and $0.5 \%$ in the TA-ER, saline-placebo and TAcs groups, respectively). 
Table 3 Summary of adverse events

\begin{tabular}{lccc}
\hline & TA-ER 32 $\mathbf{~ m g}$ & $\begin{array}{c}\text { Saline-placebo } \\
\mathbf{N}=\mathbf{2 6 2}\end{array}$ & $\begin{array}{c}\text { TAcs 40 mg } \\
\mathbf{N}=\mathbf{2 1 2}\end{array}$ \\
\hline$\geq 1$ TEAE, $n$ (\%) & $168(51.9)$ & $129(49.2)$ & $119(56.1)$ \\
Grade 1 & $78(24.1)$ & $51(19.5)$ & $54(25.5)$ \\
Grade 2 & $77(23.8)$ & $65(24.8)$ & $59(27.8)$ \\
Grade 3 & $11(3.4)$ & $13(5.0)$ & $4(1.9)$ \\
Grade 4 & $2(0.6)$ & 0 & $2(0.9)$ \\
$\geq 1$ serious TEAE & $10(3.1)$ & $3(1.1)$ & $4(1.9)$ \\
$\geq 1$ TEAE leading to study discontinuation & $4(1.2)$ & $2(0.8)$ & $1(0.5)$ \\
TEAE by maximum relationship & & & \\
Not related & $133(41.0)$ & $108(41.2)$ & $93(43.9)$ \\
Unlikely & $18(5.6)$ & $13(5.0)$ & $13(6.1)$ \\
Possibly, probably, or definitely related & $17(5.2)$ & $8(3.1)$ & $13(6.1)$ \\
$\geq 1$ index-knee TEAE & $53(16.4)$ & $37(14.1)$ & $22(10.4)$ \\
$\geq 1$ index-knee TEAE leading to study discontinuation & $3(0.9)$ & $2(0.8)$ & $1(0.5)$ \\
\hline
\end{tabular}

$T A c s$ triamcinolone acetonide crystalline suspension, $T A$-ER triamcinolone acetonide extended-release, TEAE treatmentemergent adverse event

\section{DISCUSSION}

In this pooled analysis of three phase $2 / 3$ clinical trials, TA-ER provided pain relief as shown by significant and sustained reductions in rescue medication use from baseline. In addition, patients treated with TA-ER required less rescue medication throughout the studies than patients treated with saline-placebo or TAcs. The safety profiles of TA-ER, saline-placebo, and TAcs were similar in this pooled analysis and consistent with that in the individual studies.

Providing rescue medication to patients participating in OA clinical trials can prevent dropout due to episodes of acute breakthrough pain or lack of efficacy and can provide an alternative way of measuring pain relief across treatment arms. The use of rescue medication is a clinically important indicator of analgesic efficacy and can be a secondary or an exploratory outcome measure in OA studies $[16,17]$. The current analysis adds to the efficacy profile of TA-ER by demonstrating a reduced need for secondary pain medication, which would potentially lower the cumulative exposure of a patient to the adverse effects of oral agents $[13,14]$.

The current analysis is limited by its pooled retrospective nature. This led to differences in the number of patients receiving each treatment because of differences in individual study designs and durations. In addition, the allowance to use rescue medication for any worsening pain, not limited to OA knee pain, may have confounded the results; however, given the fact that these were large randomized trials, the impact of this potential confounder was considered to be minimal.

\section{CONCLUSIONS}

In patients with painful OAK, TA-ER treatment reduced rescue medication use compared with saline-placebo and TAcs. These findings provide another indication of analgesic benefit of TA-ER 
beginning at week 1 and lasting throughout 24 weeks. Reducing concomitant analgesic medication use in this patient population may be an additional benefit of TA-ER treatment.

\section{ACKNOWLEDGEMENTS}

The authors thank the patients who participated in the trials. The authors also thank James R. Johnson, Ph.D. (formerly employed by Summit Analytical, Denver, CO) for biostatistical support and Hessam Aazami, M.D., for contributions during development of the poster presentation at PAINWeek 2017. Philip G. Conaghan is supported in part by the National Institute for Health Research (NIHR) Leeds Biomedical Research Centre. The views expressed are those of the author(s) and not necessarily those of the NHS, the NIHR, or the Department of Health.

Funding. These studies and all article processing charges were funded by Flexion Therapeutics, Inc., Burlington, MA, USA. All authors had full access to all the data in these studies and take complete responsibility for the integrity of the data and accuracy of the data analysis.

Medical Writing, Editorial, and Other Assistance. Professional medical writing and editorial assistance in the preparation of this article was provided by Jennifer Jaworski, ApotheCom, Yardley, PA. Support for this assistance was funded by Flexion Therapeutics, Inc.

Authorship. All named authors meet the International Committee of Medical Journal Editors (ICMJE) criteria for authorship for this article, take responsibility for the integrity of the work as a whole, and have given their approval for this version to be published.

Disclosures. Alan Kivitz served on advisory panels for Janssen, Pfizer, UCB, Genzyme, Sanofi, Regeneron, and Boehringer Ingelheim, has been a consultant for SUN Pharma Advanced Research, owns stock/shares in Novartis, and declares other relationships with Genentech, Merck, and Flexion. Philip G. Conaghan has received compensation for consultancies from AbbVie, Flexion Therapeutics, Inc., Infirst, Medivir, Merck Serono, Novartis, and ONO Pharmaceutical Co. Amy Cinar is an employee of Flexion Therapeutics, Inc., and owns stock/stock options in Flexion Therapeutics, Inc. Scott Kelley is an employee of Flexion Therapeutics, Inc., and owns stock/stock options in Flexion Therapeutics, Inc. Joelle Lufkin is a former employee of Flexion Therapeutics, Inc., and owns stock/stock options in Flexion Therapeutics, Inc. Joelle Lufkin is now an Independent Consultant, Beverly, MA, USA.

Compliance with Ethics Guidelines. All procedures were conducted in accordance with the ethical standards of the responsible committee on human experimentation (institutional and national) and with the Helsinki Declaration of 1964, as revised in 2013. The protocols of the three clinical studies contributing information to the pooled analyses were approved by governing ethical bodies at the participating sites, and patients provided written informed consent before any studyrelated procedures.

Data Availability. The datasets generated during and/or analyzed during the current analysis are available from the corresponding author on reasonable request.

Open Access. This article is distributed under the terms of the Creative Commons Attribution-NonCommercial 4.0 International License (http://creativecommons.org/licenses/ by-nc/4.0/), which permits any noncommercial use, distribution, and reproduction in any medium, provided you give appropriate credit to the original author(s) and the source, provide a link to the Creative Commons license, and indicate if changes were made. 


\section{REFERENCES}

1. Center for Disease Control and Prevention. Osteoarthritis fact sheet. 2018. https://www.cdc. gov/arthritis/basics/osteoarthritis.htm. Accessed 16 Dec 2018.

2. Osteoarthritis Research Society International (OARSI). Osteoarthritis: a serious disease, submitted to the U.S. Food and Drug Administration. 2018. https://www.oarsi.org/sites/default/files/docs/2016/ oarsi_white_paper_oa_serious_disease_121416_1. pdf. Accessed 16 Dec 2018.

3. Hochberg MC, Altman RD, April KT, et al. American College of Rheumatology 2012 recommendations for the use of nonpharmacologic and pharmacologic therapies in osteoarthritis of the hand, hip, and knee. Arthritis Care Res (Hoboken). 2012;64:465-74.

4. McAlindon TE, Bannuru RR, Sullivan MC, et al. OARSI guidelines for the non-surgical management of knee osteoarthritis. Osteoarthritis Cartilage. 2014;22:363-88.

5. Trelle S, Reichenbach S, Wandel S, et al. Cardiovascular safety of non-steroidal anti-inflammatory drugs: network meta-analysis. BMJ. 2011;342:c7086.

6. Bhala N, Emberson J, Merhi A, et al. Vascular and upper gastrointestinal effects of non-steroidal antiinflammatory drugs: meta-analyses of individual participant data from randomised trials. Lancet. 2013;382:769-79.

7. Craig DG, Bates CM, Davidson JS, Martin KG, Hayes PC, Simpson KJ. Staggered overdose pattern and delay to hospital presentation are associated with adverse outcomes following paracetamol-induced hepatotoxicity. $\mathrm{Br} \mathrm{J}$ Clin Pharmacol. 2012;73:285-94.

8. Derendorf H, Mollmann H, Gruner A, Haack D, Gyselby G. Pharmacokinetics and pharmacodynamics of glucocorticoid suspensions after intraarticular administration. Clin Pharmacol Ther. 1986;39:313-7.

9. Juni P, Hari R, Rutjes AW, et al. Intra-articular corticosteroid for knee osteoarthritis. Cochrane Database Syst Rev. 2015. https://doi.org/10.1002/ 14651858.CD005328.pub3

10. Kraus VB, Conaghan PG, Aazami HA, et al. Synovial and systemic pharmacokinetics (PK) of triamcinolone acetonide (TA) following intra-articular (IA) injection of an extended-release microsphere-based formulation (FX006) or standard crystalline suspension in patients with knee osteoarthritis (OA). Osteoarthritis Cartilage. 2018;26:34-42.
11. Russell SJ, Sala R, Conaghan PG, et al. Triamcinolone acetonide extended-release in patients with osteoarthritis and type 2 diabetes: a randomized, phase 2 study. Rheumatology (Oxford). 2018;57:2235-41.

12. Bodick N, Lufkin J, Willwerth C, et al. FX006 prolongs the residency of triamcinolone acetonide in the synovial tissues of patients with knee osteoarthritis [OARSI abstract 267]. Osteoarthritis Cartilage. 2013;21:S144-5.

13. Bodick N, Lufkin J, Willwerth C, et al. An intraarticular, extended-release formulation of triamcinolone acetonide prolongs and amplifies analgesic effect in patients with osteoarthritis of the knee: a randomized clinical trial. J Bone Joint Surg Am. 2015;97:877-88.

14. Conaghan PG, Hunter DJ, Cohen SB, et al. Effects of a single intra-articular injection of a microsphere formulation of triamcinolone acetonide on knee osteoarthritis pain: a double-blinded, randomized, placebo-controlled, multinational study. J Bone Joint Surg Am. 2018;100:666-77.

15. Conaghan PG, Cohen SB, Berenbaum F, Lufkin J, Johnson JR, Bodick N. Brief report: a phase IIb trial of a novel extended-release microsphere formulation of triamcinolone acetonide for intraarticular injection in knee osteoarthritis. Arthritis Rheumatol. 2018;70:204-11.

16. Zeidler H. Paracetamol and the placebo effect in osteoarthritis trials: a missing link? Pain Res Treat. 2011;2011:696791.

17. US Department of Health and Human Services. Guidance for industry: analgesic indications: developing drug and biological products. 2014. https://www.fda.gov/downloads/drugs/guidancecom plianceregulatoryinformation/guidances/ucm 3846 91.pdf. Accessed 14 Feb 2019.

18. He WW, Kuang MJ, Zhao J, et al. Efficacy and safety of intraarticular hyaluronic acid and corticosteroid for knee osteoarthritis: a meta-analysis. Int J Surg. 2017;39:95-103.

19. Altman RD, Rosen JE, Bloch DA, Hatoum HT, Korner P. A double-blind, randomized, saline-controlled study of the efficacy and safety of EUFLEXXA for treatment of painful osteoarthritis of the knee, with an open-label safety extension (the FLEXX trial). Semin Arthritis Rheum. 2009;39:1-9.

20. Navarro-Sarabia F, Coronel P, Collantes E, et al. A 40-month multicentre, randomised placebo-controlled study to assess the efficacy and carry-over effect of repeated intra-articular injections of hyaluronic acid in knee osteoarthritis: the AMELIA project. Ann Rheum Dis. 2011;70:1957-62. 
21. Arendt-Nielsen L, Jiang GL, DeGryse R, Turkel CC. Intra-articular onabotulinumtoxinA in osteoarthritis knee pain: effect on human mechanistic pain biomarkers and clinical pain. Scand J Rheumatol. 2017;46:303-16.

22. Berenbaum F, Grifka J, Cazzaniga S, et al. A randomised, double-blind, controlled trial comparing two intra-articular hyaluronic acid preparations differing by their molecular weight in symptomatic knee osteoarthritis. Ann Rheum Dis. 2012;71:1454-60.

23. Maheu E, Zaim M, Appelboom T, et al. Comparative efficacy and safety of two different molecular weight (MW) hyaluronans F60027 and Hylan G-F20 in symptomatic osteoarthritis of the knee (KOA). Results of a non inferiority, prospective, randomized, controlled trial. Clin Exp Rheumatol. 2011;29:527-35.
24. Altman R, Asch E, Bloch D, et al. Development of criteria for the classification and reporting of osteoarthritis. Classification of osteoarthritis of the knee. Diagnostic and Therapeutic Criteria Committee of the American Rheumatism Association. Arthritis Rheum. 1986;29:1039-49.

25. Kellgren JH, Lawrence JS. Radiological assessment of osteo-arthrosis. Ann Rheum Dis. 1957;16:494-502.

26. Cleeland CS, Ryan KM. Pain assessment: global use of the Brief Pain Inventory. Ann Acad Med Singapore. 1994;23:129-38.

27. Dworkin RH, Turk DC, Farrar JT, et al. Core outcome measures for chronic pain clinical trials: IMMPACT recommendations. Pain. 2005;113:9-19. 